\title{
High-carb or low-carb, that is a question
}

\author{
Hirobumi Igawa $^{1} \cdot$ Toshinari Takamura ${ }^{1}$
}

Received: 31 October 2016/Published online: 11 November 2016

(C) The Japan Diabetes Society 2016

Keywords Obesity · Macronutrient · Energy expenditure · Body composition

\section{Introduction}

The content of our diet as well as the mode of consumption remains a central topic of debate with respect to diabetes, obesity, and longevity. In particular, the macronutrient balance may affect health because there is cross-talk among metabolic pathways for carbohydrates, fat, and protein [1]. In this commentary, we overview very recent advances in the understanding of the effects of the macronutrient balance on body composition and energy metabolism.

\section{Restriction of dietary carbohydrate does not contribute to body fat loss in humans}

In 2016, Hall et al. showed that a ketogenic diet (KD; $2400 \mathrm{kcal} / \mathrm{day}, 6 \%$ carbohydrate, $77 \%$ fat, $17 \%$ protein) was not accompanied by decreased body fat in obese people [2]. In this study, 17 men classified as overweight or obese were admitted to metabolic wards, where they consumed a high-carbohydrate baseline diet (BD; $2400 \mathrm{kcal} /$ day, $48 \%$ carbohydrate, $35 \%$ fat, $17 \%$ protein) for 4 weeks followed by 4 weeks of KD. Hall et al. measured energy

Toshinari Takamura

ttakamura@m-kanazawa.jp

1 Department of Endocrinology and Metabolism, Kanazawa University Graduate School of Medical Sciences, 13-1 Takara-machi, Kanazawa, Ishikawa 920-8640, Japan expenditure by metabolic chambers during each diet period.

Energy expenditure transiently increased by $100 \mathrm{kcal} /-$ day in the first week of the KD period. However, this change was limited, and there was no significant difference between $\mathrm{BD}$ and $\mathrm{KD}$ at the study endpoint, which suggests that the proportion of carbohydrate to fat in the diet had little effect on energy expenditure.

The subjects lost $0.8 \mathrm{~kg}$ of body weight with a reduction in body fat of $-0.5 \mathrm{~kg}$ during the BD period, while the subjects lost $2.2 \mathrm{~kg}$ of body weight with a reduction in body fat of $-0.5 \mathrm{~kg}$ during the $\mathrm{KD}$ period. Body weight significantly decreased in the KD period compared to that in the $\mathrm{BD}$ period, but there was no significant difference in body fat loss between KD and BD. In the early phase of $\mathrm{KD}$, body weight rapidly decreased by $1.6 \mathrm{~kg}$, despite a body fat loss of only $0.2 \mathrm{~kg}$ and increased urinary nitrogen excretion, suggesting that body water loss or skeletal muscle loss might contribute to body weight loss during the KD period.

This study indicates that the restriction of dietary carbohydrate does contribute to body weight loss but not to body fat loss.

\section{Altered adaptation to macronutrient oxidation underlies reduced fat diet-induced body fat loss}

The same group (Hall et al.) investigated the mechanisms underlying altered body fat loss between a low-carbohydrate diet and a low-fat diet in humans by precisely estimating the energy balance and macronutrient oxidation [3]. In this study, 19 people classified as obese (mean BMI $36 \mathrm{~kg} / \mathrm{m}^{2}$ ) were admitted to metabolic wards. The subjects had an energy-balanced diet $(2740 \mathrm{kcal} / \mathrm{day}, 50 \%$ carbohydrate, 
Table 1 The comparative effects of dietary carbohydrate and fat on energy expenditure and body fat

\begin{tabular}{lll}
\hline & Carbohydrate vs. fat & \\
\cline { 2 - 3 } & $\begin{array}{l}\text { Low carbohydrate } \\
\text { (high fat) less calorie }\end{array}$ & $\begin{array}{l}\text { Low fat (high } \\
\text { carbohydrate) } \\
\text { less calorie }\end{array}$ \\
\hline Energy expenditure & $\downarrow \downarrow$ & $\downarrow$ \\
Oxidation & $\uparrow$, soon achieves plateau & $\rightarrow$ \\
Fat & $\downarrow \downarrow$ & $\rightarrow$ \\
Carbohydrate & $\downarrow$ & $\downarrow \downarrow$ \\
Body fat & & \\
\hline
\end{tabular}

Table 2 The comparative effects of dietary carbohydrate and protein on energy expenditure and body fat

\begin{tabular}{|c|c|c|}
\hline & \multicolumn{2}{|c|}{ Carbohydrate vs. protein } \\
\hline & $\begin{array}{l}\text { Low carbohydrate } \\
\text { (high protein) } \\
\text { Ad libitum }\end{array}$ & $\begin{array}{l}\text { Low protein } \\
\text { (high carbohydrate) } \\
\text { Ad libitum }\end{array}$ \\
\hline Food intake & $\rightarrow$ & $\uparrow$ \\
\hline Energy expenditure & $\rightarrow$ & $\uparrow$ \\
\hline Body fat & $\rightarrow$ & $\downarrow$ \\
\hline
\end{tabular}

$35 \%$ fat, $15 \%$ protein) for 5 days followed by a random assignment for 6 days to a 30\% calorie-restricted diet, with a restriction placed on the intake of carbohydrate (RC: $1918 \mathrm{kcal} /$ day, $29 \%$ carbohydrate, $50 \%$ fat, $21 \%$ protein) or fat (RF: $1918 \mathrm{kcal} / \mathrm{day}, 71 \%$ carbohydrate, $8 \%$ fat, $21 \%$ protein). RC had a $60 \%$ restriction of dietary carbohydrate. RF had an $85 \%$ restriction of dietary fat. The investigators measured the energy balance and macronutrient oxidation by metabolic chambers before and after each diet.

Although there was no significant difference in the energy expenditure between $\mathrm{RC}$ and $\mathrm{RF}, \mathrm{RF}$ resulted in greater cumulative body fat loss (Table 1). The differences in fat loss were due to transient differences in carbohydrate balance concurrent with persistent differences in fat balance. Initially, in $\mathrm{RC}$, fat oxidation rapidly increased by $600 \mathrm{kcal} /$ day and carbohydrate oxidation decreased by $600 \mathrm{kcal} /$ day. However, the fat oxidation achieved a plateau due to adaptation to the carbohydrate restriction after several days, whereas the carbohydrate oxidation kept decreasing without adaptation (Table 1). In contrast, RF resulted in minimal adaptation to carbohydrate and fat restriction, thereby leading to greater fat loss than RC (Table 1).

It is perplexing that in spite of no difference in the energy balance between RC and RF, RC resulted in greater weight loss than RF. A few previous studies indicate that weight loss by restriction of carbohydrate intake is involved in skeletal muscle mass loss [4, 5]. In RC, protein oxidation slightly increased, which might lead to skeletal muscle loss. It is possible that reduced insulin secretion contributed to the increased protein oxidation.

Unexpectedly in the study by Hall et al. [3], RF decreased the plasma levels of ghrelin, a hormone stimulating appetite, whereas RC increased it. This suggests that RF decreases appetite compared to RC.

\section{A low protein-high carbohydrate diet decreases body fat in mice}

Recent studies in Drosophila and mice revealed that low protein-high carbohydrate (LPHC) diets increased the lifespan, whereas a reduction in the total energy intake had no positive impact on longevity [6, 7]. In mice, branched-chain amino acids contribute to the development of obesity-associated insulin resistance in a highfat diet [8]. In the liver, obesity-induced insulin resistance is induced by chronic endoplasmic reticulum stress [9], which is caused by defective protein degradation $[10,11]$ and possibly by excessive intake and synthesis of proteins [1].

Solon-Biet et al. showed in mice that the LPHC diet caused greater body fat loss than a high protein-low carbohydrate (HPLC) diet [12] (Table 2). The LPHC diet increased energy intake compared to the HPLC diet because of the phenomena of protein leverage, where the protein intake is prioritized over fat and carbohydrate intake [13]. In spite of the increase in the energy intake, the LPHC diet reduced body fat mass because of increased energy expenditure (Table 2), which is consistent with increased diet-induced thermogenesis serving to consume excess energy and slow development of adiposity [14]. This study suggests that a diet replacing carbohydrate with protein may be of little advantage in body fat reduction.

\section{Conclusion}

The studies reviewed in this commentary clearly reject the claim that carbohydrate restriction is required for body fat loss, at least with respect to energy oxidation and balance. However, it remains controversial to recommend a definite nutrient balance [15]. In particular, the effects of a high or low carbohydrate diet on body fat are still a debatable issue. To confirm the content of a diet and the mode of consumption for the purpose of body fat loss, long-term and large-scale clinical evidence is required. 


\section{Compliance with ethical standards}

Conflict of interest $\mathrm{H}$. Igawa declares that he has no conflict of interest. T. Takamura received lecture fees from Mitsubishi Tanabe Pharma Corp., AstraZeneca K.K., Astellas Pharma Inc., MSD K.K., and Daichi Sankyo Co. Ltd.

Human rights statement and informed consent This article does not report any original studies with human or animal subjects that were performed by any of the authors.

\section{References}

1. Takamura T. Remodeling of nutrient homeostasis by unfolded protein response. Diabetes. 2014;63(3):841-3. doi:10.2337/db131721.

2. Hall KD, Chen KY, Guo J, et al. Energy expenditure and body composition changes after an isocaloric ketogenic diet in overweight and obese men. Am J Clin Nutr. 2016;104(2):324-33. doi:10.3945/ajcn.116.133561.

3. Hall KD, Bemis T, Brychta R, et al. Calorie for calorie, dietary fat restriction results in more body fat loss than carbohydrate restriction in people with obesity. Cell Metab. 2015;22(3):427-36. doi:10.1016/j.cmet.2015.07.021.

4. Yang MU, Van Itallie TB. Composition of weight lost during short-term weight reduction. Metabolic responses of obese subjects to starvation and low-calorie ketogenic and nonketogenic diets. J Clin Invest. 1976;58(3):722-30. doi:10.1172/JCI108519.

5. Vazquez JA, Kazi U, Madani N. Protein metabolism during weight reduction with very-low-energy diets: evaluation of the independent effects of protein and carbohydrate on protein sparing. Am J Clin Nutr. 1995;62(1):93-103.

6. Lee KP, Simpson SJ, Clissold FJ, et al. Lifespan and reproduction in Drosophila: new insights from nutritional geometry. Proc Natl Acad Sci USA. 2008;105(7):2498-503. doi:10.1073/pnas. 0710787105.
7. Solon-Biet SM, McMahon AC, Ballard JWO, et al. The ratio of macronutrients, not caloric intake, dictates cardiometabolic health, aging, and longevity in ad libitum-fed mice. Cell Metab. 2014;19(3):418-30. doi:10.1016/j.cmet.2014.02.009.

8. Newgard CB, An J, Bain JR, et al. A branched-chain amino acidrelated metabolic signature that differentiates obese and lean humans and contributes to insulin resistance. Cell Metab. 2009;9(4):311-26. doi:10.1016/j.cmet.2009.02.002.

9. Ozcan U, Cao Q, Yilmaz E, et al. Endoplasmic reticulum stress links obesity, insulin action, and type 2 diabetes. Science. 2004;306(5695):457-61. doi:10.1126/science.1103160.

10. Yang L, Li P, Fu S, Calay ES, Hotamisligil GS. Defective hepatic autophagy in obesity promotes ER stress and causes insulin resistance. Cell Metab. 2010;11(6):467-78. doi:10.1016/j.cmet. 2010.04.005.

11. Otoda T, Takamura T, Misu H, et al. Proteasome dysfunction mediates obesity-induced endoplasmic reticulum stress and insulin resistance in the liver. Diabetes. 2013;62(3):811-24. doi: $10.2337 / \mathrm{db} 11-1652$.

12. Solon-Biet SM, Mitchell SJ, Coogan SCP, et al. Dietary protein to carbohydrate ratio and caloric restriction: comparing metabolic outcomes in mice. Cell Rep. 2015;11(10):1529-34. doi:10.1016/j. celrep.2015.05.007.

13. Simpson SJ, Raubenheimer D. Obesity: the protein leverage hypothesis. Obes Rev. 2005;6(2):133-42. doi:10.1111/j.1467789X.2005.00178.x.

14. Huang X, Hancock DP, Gosby AK, et al. Effects of dietary protein to carbohydrate balance on energy intake, fat storage, and heat production in mice. Obesity (Silver Spring). 2013;21(1):85-92. doi:10.1002/oby.20007.

15. Tobias DK, Chen M, Manson JE, Ludwig DS, Willett W, Hu FB. Effect of low-fat diet interventions versus other diet interventions on long-term weight change in adults: a systematic review and meta-analysis. Lancet Diabet Endocrinol. 2015;3(12):968-79. doi:10.1016/S2213-8587(15)00367-8. 